\title{
Physical Asset Management in Equipment-Oriented Industries Using the Equipment Life Cycle Management Approach
}

\author{
Hassan Adshirinpour, Mohammad Mehdi Movahhedi, Hedieh Divsalar, Shahla Sohrabi
}

\begin{abstract}
Proper assets management and maintenance, especially equipment in the value chain of an organization, the failure of which leads to interruptions in the system and waiting in the production line, are very vital and of special importance in "equipment-oriented" organizations, including industries such as oil, gas, petrochemicals, steel, minerals, companies involved in the production and distribution of water, electricity, etc. Usually such organizations have a constant need to create an efficient and effective life cycle in order to achieve an efficient physical asset management system. The present study aimed to investigate the physical assets management in equipment-oriented industries with the equipment life cycle management (resource-based) view in oil and gas industries with a case study in an upstream oil industry company (namely North Drilling Company). For this purpose, first 15 criteria have been obtained based on literature review and research literature for evaluating the performance of physical asset management in oil and gas companies. Then, eight of the most important performance evaluation criteria were determined based on experts' opinions and the fuzzy Delphi method, and in the next step, these criteria were weighted using the fuzzy SWARA method. According to the results, the most important criterion is the cost of maintenance and the least important is the cost of service-support. Finally, solutions are presented in the form of practical suggestions to improve the physical asset management system in this company.
\end{abstract}

Keywords: fuzzy Delphi; fuzzy SWARA; equipment life cycle; oil and gas equipment-oriented industries; physical asset management

\section{INTRODUCTION}

As one of the most important organizational assets, physical assets include financial, human, knowledge, and information technology assets that have four life cycle periods, namely acquisition, operation, maintenance, and retiring (decommissioning), which indicates the life of an equipment or a part from birth to the end of its life, in terms of the quality of operation of the equipment (less down time and more up time). The result of monitoring and managing the life cycle of equipment is to achieve high work efficiency and low cost of equipment life cycle, which will increase the profitability of stakeholders in the value chain of organizations in addition to creating high safety in equipment [1]. Accordingly, the organization's resources are grouped into five categories as follows, including financial, human, information technology, knowledge and physical assets:

1) Knowledge asset management

2) IT asset management

3) Human resource asset management

4) Financial asset management

5) Physical asset management

The physical asset management system has been studied from two perspectives in the United Kingdom and Canada. In the first model, Jon Wood House follows the Life Cycle Management emphasizing low equipment cost (LCC) and increased equipment efficiency (up time). In the second method, Jon Campbell from Canada applies the method of increasing the equipment reliability and accessibility so that the operation does not stop and the production line continues operating. In the present paper, a physical asset management system evaluation model is developed with an emphasis on the oil and gas industry and the Northern Drilling Company, as a leading company in the upstream oil industry, is investigated as the case study.

\section{LITERATURE REVIEW AND RESEARCH BACKGROUND}

In Standard Norg (2014) research, asset management is defined as "coordinated activity of the organization to realize the value of assets" and then an explanation is provided on the term "activity" and the term value realization. Activities can take many forms, tangible and intangible. Examples of activities related to the realization of asset value can include different sets of approach, planning and implementation of programs. When it comes to generating and gaining value because of improving asset management, it often includes balancing opportunities and risks as well as cost and performance [2]. Close attention should be paid to asset management by all stages of the life cycle, including planning, design, procurement, construction, operations, and disposal. Existing EAM processes are usually planned and executed during the asset life cycle. Therefore, the effectiveness of processes is reduced despite many efforts to introduce the process. An important operational task in the drilling industry, with high cost considerations worldwide, is effective management of drilling assets.

As an important operational task in the offshore environment, effective management of drilling assets is along with numerous cost considerations around the world. Offshore rigs, especially vessels, have far more valuable assets than a conventional or offshore drilling operation, including very valuable submarine assets. Although these assets have been attached to rigs for a long time, they are still brought from dock to rig and from rig to maintenance operations and inspection programs, as well as to support variable operational needs.

Today, oil and gas companies are deploying new technologies to achieve higher efficiency, and management is pushing engineers and maintenance to reduce budgets, labour, and operating costs as the production levels increase. There is also more exposure to a variety of risks in terms of health safety and the environment due to new challenges 
facing operators in unusual and new geographical areas. Now more than ever, it is important to set the right policies and measures to meet compliance requirements and manage risk and security breaches efficiently and with cost-effective policies and measures for good asset management.

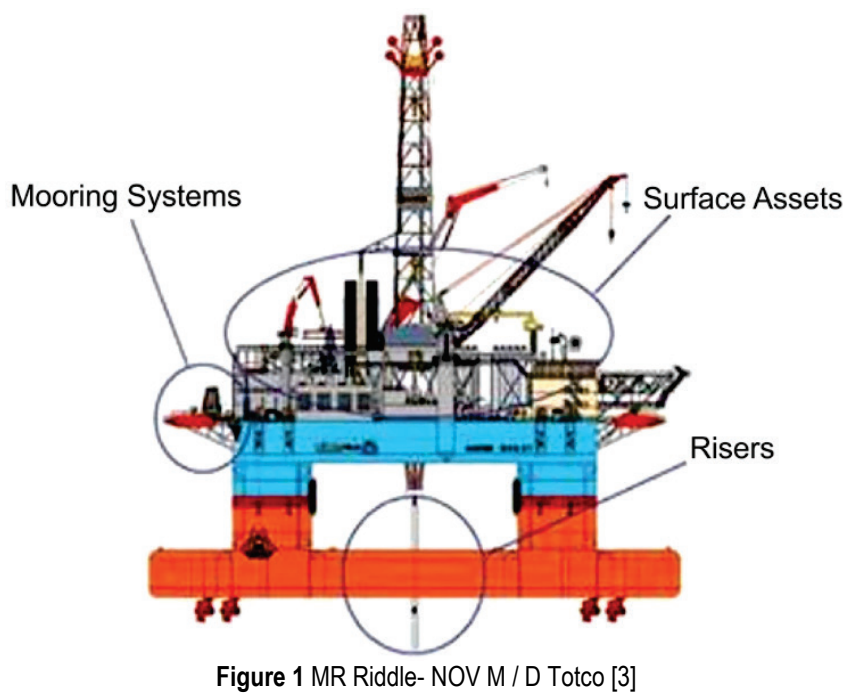

The following can be mentioned regarding the recent research on this issue [4].

Advanced maintenance management system by Vahedi et al. (2017) has been evaluated with the approach of physical asset management in South Pars Oil and Gas Complex of Iran. In this research, the combined method of balanced scorecard evaluation system and fuzzy hierarchical analysis process model have been used. According to the hexagonal system of balanced scorecard, evaluation criteria include internal processes, financial, organizational stakeholders, learning, employee satisfaction and the organization's environment. Measuring effectiveness coefficients of the evaluation criteria were performed through a fuzzy hierarchical analysis process model. Data were collected through interviews with oil industry experts in the field of physical asset management. Using a hexagonal score card system increases the probability of correctness of the results of the evaluation system. According to the results, internal and financial processes, organizational environment, learning, stakeholders of the organization, and satisfaction, with weights equal to $29 \%, 18 \%, 17 \%, 5 \%$, and $2 \%$ show the performance of physical asset management system in the organization, respectively $[5,6]$.

Management performance in the field of physical asset management (PAM) has been evaluated by Khojastehpour et al (2020) in Iran Khodro Company. The researchers concluded that due to the existence of extensive and expensive equipment and the need for careful planning for their life cycle in the industries such as oil and gas, petrochemicals and automobiles, indicators related to evaluating asset management performance should be carefully selected and evaluated. Hence, it is better to consider items such as the extent to which objective goals are achieved, the timing of monitoring and measurement, quality and reliability in the performance evaluation [5].
A conceptual model of procurement strategy for the physical asset management framework has been developed by Joa et al. (2014) and the researchers believe that little research has been done on the physical asset management framework in the oil and gas industry. They developed a framework in this regard considering the theory of reliability and the Business Continuity Theory (BCT) and proposed their conceptual model from two perspectives of supply risk and strategic purchasing.

Physical asset management in the oil and gas industry with the smart asset management approach has been considered in the research of Nell et al. (2016). This article discusses the use of new concepts in the Internet of Things (IoT) and block chain in physical asset management. Also, by reviewing the management of intelligent physical assets in this industry, an attempt has been made to achieve the goal of the research, i.e. to make the industry aware of the potential of combining SAM with these concepts in strategic management decision making [6].

In a study conducted by Nixon et al. (2019), the evolution of physical asset management with respect to the topics of digitalization and new sciences has been studied and various analyses have been performed in this field. These researchers used the use of the Internet of Things and other new technologies, such as artificial intelligence, etc., in effective physical asset management, and found, for example, that insurance costs lead to a reduction and costeffectiveness using the digitization approach. It saves about $\$ 750$ billion in insurance companies around the world [7].

The challenges of asset integrity management in offshore rig drilling has been addressed in Mayang et al. (2016). In this paper, the challenges and possible factors affecting the management of asset integrity in offshore facilities have been identified and analysed in order to obtain the main reasons for these challenges and solutions to solve them using this research [8].

Accordingly, research on physical asset management and performance appraisal in the oil and gas industry is very limited. Therefore, the present study aimed to develop a model for evaluating the physical asset management system in oil and gas companies.

\section{RESEARCH METHOD}

The present study is an applied research, which is conducted with the descriptive survey and correlational approach. This research presents a model for evaluating the physical asset system, for which first the physical asset management evaluation indicators are extracted and selected using literature review and interviews with experts in this field and using the Delphi method. Then, with the help of ranking methods, it weighs these indicators to measure the performance of the physical asset management system in the oil and gas industry with an emphasis on the oil upstream and extraction industries. Finally, a case study of North Drilling Company as an oil upstream industry is provided and the evaluation of the physical asset system and its effects on key performance indicators identified in this study are discussed. Therefore, the present research method will be as follows: 
- $\quad$ applied research in terms of the purpose

- descriptive-survey and correlational research in terms of data collection.

The statistical population of the present study includes all companies active in the field of oil and gas, and the statistical sample consists the Northern Drilling Company, which is one of the upstream oil companies in Iran.

\section{DATA ANALYSIS}

After a thorough review of the research theoretical foundations and a detailed review of recent research in the field of implementation and evaluation of physical asset system in companies with more focus on upstream and equipment-oriented oil and gas industries, the researcher has identified and extracted physical asset management indicators in equipment-based industries with the equipment life cycle management approach as follows (in Tab. 1).

Table 1 Physical asset management indicators in equipment-based industries

\begin{tabular}{|c|l|c|}
\hline Row & \multicolumn{1}{|c|}{ Indicator } & Reference \\
\hline 1 & Maintenance and repair costs & {$[2],[5],[9],[10]$} \\
\hline 2 & Success of asset management strategies & {$[12],[13],[3]$} \\
\hline 3 & Equipment life cycle costs & {$[3],[13]$} \\
\hline 4 & Improving waste management & {$[4],[14],[15]$} \\
\hline 5 & Increasing sales volume & {$[5],[6]$} \\
\hline 6 & Cost of capital & {$[6],[2],[1],[4]$} \\
\hline 7 & Accessibility and reliability levels & {$[16],[17]$} \\
\hline 8 & Manpower costs & {$[10],[2],[5]$} \\
\hline 9 & Equipment risk taking $[19],[2]$ \\
\hline 10 & Facilitating observance of regulations & {$[20],[21]$} \\
\hline 11 & Annual logistics fee & {$[22],[23],[5]$} \\
\hline 12 & Cost of support services & {$[24],[9]$} \\
\hline 13 & Reducing environmental warnings etc. & {$[4],[2],[5]$} \\
\hline 14 & Increasing return on investment & {$[2],[17]$} \\
\hline 15 & Spare parts service level & {$[10],[7],[6],[5],[15]$} \\
\hline
\end{tabular}

Then, the most important indicators were identified using fuzzy Delphi and fuzzy SWARA methods and were weighted in North Drilling Company.
20 out of 25 experts in the field of study participated in the present study. Details of the 20 experts are given in Tab. 2 in the Board of Experts section. Therefore, the questionnaire was distributed among them and they answered the questions carefully. In this step, the fuzzy value of each research question is calculated using the experts' opinions, and the fuzzy value of the answers to each question is obtained through triangular fuzzy numbers according to Tab. 2 too.

\begin{tabular}{|c|c|c|c|c|}
\hline \multirow{2}{*}{$\begin{array}{l}\text { Type of activity of } \\
\text { experts }\end{array}$} & \multirow{2}{*}{ QTY } & \multicolumn{3}{|c|}{$\begin{array}{c}\text { Background and expertise in the field of } \\
\text { physical asset management }\end{array}$} \\
\hline & & 5 to 7 years & 7 to 10 years & $\begin{array}{l}\text { More than } \\
10 \text { years }\end{array}$ \\
\hline $\begin{array}{l}\text { Deputies and senior } \\
\text { managers and } \\
\text { supervisors of the } \\
\text { organization under } \\
\text { study }\end{array}$ & 20 & 4 & 7 & 9 \\
\hline Limits & \multicolumn{4}{|c|}{$\begin{array}{l}\text { Triangular fuzzy value of the } i^{\text {th }} \text { question of } \\
\text { questionnaire }\end{array}$} \\
\hline Upper limit & \multicolumn{4}{|c|}{$\begin{array}{c}\text { maximum value allocated to the } i^{\text {th }} \text { question of } \\
\text { questionnaire }\end{array}$} \\
\hline Intermediate limit & \multicolumn{4}{|c|}{$\begin{array}{l}\text { Geometric average of all expert opinions on to the } \\
i^{\text {th }} \text { question of questionnaire }\end{array}$} \\
\hline Lower limit & \multicolumn{4}{|c|}{$\begin{array}{c}\text { The minimum value allocated to the } i^{\text {th }} \text { question of } \\
\text { questionnaire }\end{array}$} \\
\hline
\end{tabular}

Tab. 3 indicates the frequency of answers provided by these experts based on the 5-point Likert scale of the research questionnaire.

According to the table above, the fuzzy value of each question is considered as a triangular fuzzy number $(U, M, L)$ so that the lower limit value of this triangular fuzzy number for each question is equal to the minimum value assigned by experts from the Likert scale (1 to 5); the middle of this fuzzy number is the calculation of the geometric mean of all expert opinions on the questions and the upper limit of this triangular fuzzy number is the maximum value assigned by experts from the Likert scale; the fuzzy value of each question is displayed in Tab. 4 below.

Table 3 Frequency of Likert scale answers to the research questionnaire

\begin{tabular}{|c|c|c|c|c|c|c|}
\hline \multirow{2}{*}{ No. of question } & \multicolumn{5}{|c|}{ Scale } & \multirow[b]{2}{*}{ No. of experts } \\
\hline & Very low (1) & Low (2) & Medium (3) & High (4) & Very high (5) & \\
\hline 20 & 11 & 6 & 2 & & 1 & 1 \\
\hline 20 & & & 5 & 7 & 8 & 2 \\
\hline 20 & 4 & 14 & & 2 & & 3 \\
\hline 20 & & 1 & 5 & 10 & 4 & 4 \\
\hline 20 & & & 2 & 7 & 11 & 5 \\
\hline 20 & 2 & 13 & 3 & 1 & 1 & 6 \\
\hline 20 & 12 & 6 & 2 & & & 7 \\
\hline 20 & & & 1 & 6 & 13 & 8 \\
\hline 20 & 1 & 16 & 2 & 1 & & 9 \\
\hline 20 & & & 5 & 7 & 8 & 10 \\
\hline 20 & 7 & 10 & 3 & & & 11 \\
\hline 20 & 10 & 9 & 1 & & & 12 \\
\hline 20 & & & 3 & 3 & 14 & 13 \\
\hline 20 & & & 1 & 12 & 7 & 14 \\
\hline 20 & 2 & 14 & 4 & & & 15 \\
\hline
\end{tabular}

According to the experts and the above table relating the threshold for items, where the score (defuzzified value) of each indicator is less than the average value (number 3 ) (red items in the above table) means that this indicator is less important and should be ignored. Seven indicators have a defuzzified value less than 3 ; so these indicators have been 
removed and only 8 indicators have been considered by the researcher. According to Tab. 5 and the condition of consensus or agreement that $70 \%$ of the experts gave the same answer to one of the options for each question, the amount of consensus is examined, considering that the amount of consensus in the table below have not reached $70 \%$ of the consensus; so the second round of the questionnaire has started and the general results of the first questionnaire will be provided to the experts to answer the questions of the second questionnaire again according to the results of the first questionnaire.

Table 4 Fuzzy value of each question

\begin{tabular}{|c|c|c|c|}
\hline No. of indicator & $U$ & $M$ & $L$ \\
\hline 5 & 4.0998 & 1 & 1 \\
\hline 3 & 1.6774 & 1 & 2 \\
\hline 5 & 3.9024 & 2 & 3 \\
\hline 4 & 1.9947 & 1 & 4 \\
\hline 3 & 1.4225 & 1 & 5 \\
\hline 5 & 3.5306 & 1 & 6 \\
\hline 5 & 4.4433 & 3 & 7 \\
\hline 3 & 1.3006 & 1 & 8 \\
\hline 5 & 3.7962 & 2 & 9 \\
\hline 3 & 1.6774 & 1 & 10 \\
\hline 5 & 4.1422 & 3 & 11 \\
\hline 5 & 4.4082 & 3 & 12 \\
\hline 3 & 1.3083 & 1 & 13 \\
\hline 3 & 1.6013 & 1 & 14 \\
\hline 5 & 3.8615 & 3 & 15 \\
\hline
\end{tabular}

Table 5 Evaluating the threshold of the first round questionnaire results

\begin{tabular}{|c|c|c|}
\hline No. of indicator & $\begin{array}{c}\text { Defuzzified value of each } \\
\text { question }\end{array}$ & $\%$ of Consensus \\
\hline 55 & 3.5499 & 1 \\
\hline 40 & 1.8387 & 2 \\
\hline 70 & 3.7012 & 3 \\
\hline 50 & 2.2470 & 4 \\
\hline 55 & 1.7112 & 5 \\
\hline 65 & 3.2653 & 6 \\
\hline 60 & 4.2216 & 7 \\
\hline 65 & 1.6503 & 8 \\
\hline 80 & 3.6481 & 9 \\
\hline 40 & 1.8387 & 10 \\
\hline 50 & 4.0711 & 12 \\
\hline 50 & 4.2041 & 13 \\
\hline 70 & 1.6541 & 14 \\
\hline 60 & 1.8006 & 15 \\
\hline 70 & 3.9307 & \\
\hline
\end{tabular}

Based on Tab. 5, it is clear that indicators 2, 4 and 5, as well as $8,10,13$ and 14 have not reached the consensus condition and are therefore considered as insignificant indicators.

Therefore, after removing the minor indicators and receiving expert opinions in the second step of the fuzzy Delphi method, the results of the studies are presented in Tab. 6.

According to the table above, all the fuzzy numbers of the questionnaires are all greater than the base number three for the new questions of the second round of the questionnaire, so this means that there are no minor questions in this second round of the questionnaire and on the other hand, the consensus percentage of all questions is also higher than the set value of $70 \%$; so the consensus is accepted and there is no need to go to the third round of fuzzy Delphi.

\begin{tabular}{|l|c|c|}
\multicolumn{1}{|c|}{ Table 6 Assessing the threshold of the second round questionnaire results } \\
\hline Selected indicators & $\begin{array}{c}\text { Defuzzified value } \\
\text { of each question }\end{array}$ & $\begin{array}{c}\% \text { of } \\
\text { Consensus }\end{array}$ \\
\hline Annual maintenance and repair costs & 70 & 4.5881 \\
\hline Equipment life cycle costs & 80 & 3.9871 \\
\hline Cost of capital & 70 & 4.0845 \\
\hline Accessibility and reliability levels & 75 & 4.3305 \\
\hline Equipment risk taking & 80 & 4.3412 \\
\hline Spare parts service level & 75 & 4.6143 \\
\hline Annual logistics fee & 85 & 3.7254 \\
\hline Cost of support services & 70 & 4.3047 \\
\hline
\end{tabular}

As it is clear, 5 of these indicators have covered the financial criteria and the other three indicators have shown the quality and performance criteria in evaluating the physical asset system in the oil and gas industry.

Second step of analysis: fuzzy SWARA

In the previous section, 8 out of the 15 identified indicators were agreed upon by experts. In other words, these 8 indicators are the most important in the field of physical asset management. Accordingly, in this step, the indicators are prioritized based on their weights. Five of the most specialized and experienced people were asked to answer the questions of the fuzzy SWARA questionnaire. The results are presented in Tab. 7.

Table 7 Analysis of fuzzy rider results

\begin{tabular}{|c|c|c|c|}
\hline \multicolumn{2}{|c|}{ Selected indicators } & $w_{j}$ & $q_{j}$ \\
\hline \multicolumn{2}{|c|}{ Annual maintenance and repair costs } & 0.400 & $(0.332,0.461,0.404)$ \\
\hline \multicolumn{2}{|c|}{ Equipment life cycle costs } & 0.263 & $(0.237,0.307,0.242)$ \\
\hline \multicolumn{2}{|c|}{ Accessibility\& reliability levels } & 0.160 & $(0.192,0.122,0.165)$ \\
\hline \multicolumn{2}{|c|}{ Cost of capital } & 0.080 & $(0.096,0.061,0.082)$ \\
\hline \multicolumn{2}{|l|}{ Spare parts service level } & 0.048 & $(0.014,0.003,0.008)$ \\
\hline \multicolumn{2}{|l|}{ Annual logistics fee } & 0.028 & $(0.062,0.022,0.059)$ \\
\hline \multicolumn{2}{|l|}{ Equipment risk taking } & 0.013 & $(0.043,0.014,0.025)$ \\
\hline \multicolumn{2}{|l|}{ Cost of support services } & 0.008 & $(0.020,0.005,0.012)$ \\
\hline$k_{j}$ & \multicolumn{2}{|c|}{$b_{j}$} & Global weight \\
\hline$(1,1,1)$ & \multicolumn{2}{|c|}{$(1,1,1)$} & $(1,1,1)$ \\
\hline$(0.714,0.666,0.599)$ & \multicolumn{2}{|c|}{$(1.4,1.5,1.667)$} & $(0.4,0.5,0.66)$ \\
\hline$(0.580,0.266,0.408)$ & \multicolumn{2}{|c|}{$(1.23,2.5,1.465)$} & $(0.23,1.5,0.46)$ \\
\hline$(0.29,0.133,0.204)$ & \multicolumn{2}{|c|}{$(2,2,2)$} & $(1,1,1)$ \\
\hline$(0.044,0.008,0.020)$ & \multicolumn{2}{|c|}{$(1.42,1.373,1.5)$} & $(0.42,0.37,0.5)$ \\
\hline$(0.189,0.048,0.148)$ & \multicolumn{2}{|c|}{$(1.53,2.74,1.37)$} & $(0.53,1.74,0.37)$ \\
\hline$(0.130,0.032,0.062)$ & \multicolumn{2}{|c|}{$(1.444,1.5,2.36)$} & $(0.444,0.5,1.36)$ \\
\hline$(0.063,0.012,0.031)$ & \multicolumn{2}{|c|}{$(2.04,2.5,2)$} & $(1.04,1.5,1)$ \\
\hline
\end{tabular}

As it is clear, the annual maintenance costs with a weight of 0.400 have the highest weight or in other words, they are in the priority of the most important indicator in the management of physical assets in the study. The support services cost index with the weight of 0.008 has the lowest weight among the selected indicators.

\subsection{Third Step of Analysis: Analysis the Gap between the Current and the Desired Situation}

In the last step, a researcher-made questionnaire was distributed among managers, deputies, and senior experts of the company under study. From a total of 3,000 employees of the company, 341 were selected based on Morgan 
sampling table at an error level of 0.05 and a questionnaire was distributed among them. Statistical Hypothesis: There is no gap between the current situation and the desired situation in the management of physical assets in the company under study. A model should be used in order to examine the research hypothesis that optimally explains the statistical hypothesis. Independent t-test is possible in a situation where a variable is examined in two statistical populations, in addition to the fact that one of the variables must be categorical (Momeni and Qayumi, 2008, pp. 71-72). However, the test used in this research is Paired sample T test. This is because this test compares two variables related to a community so that both populations must be quantitative, in addition to being a very suitable method for analysing the gap between variables and statistical hypothesis (Ibid., P. 77).

Table 8 Gap analysis with t test

\begin{tabular}{|c|c|c|c|c|}
\hline $\begin{array}{c}\text { Components and } \\
\text { factors }\end{array}$ & $\begin{array}{c}\text { Average } \\
\text { opinions in } \\
\text { the current } \\
\text { situation }\end{array}$ & $\begin{array}{c}\text { Average } \\
\text { opinions in } \\
\text { desired } \\
\text { condition }\end{array}$ & $\begin{array}{c}\text { Mean } \\
\text { difference }\end{array}$ & Sig \\
\hline $\begin{array}{c}\text { Annual } \\
\text { Maintenance and } \\
\text { Repair Costs }\end{array}$ & 0.000 & -1.04 & 4.05 & 3.01 \\
\hline $\begin{array}{c}\text { Equipment life } \\
\text { cycle costs }\end{array}$ & 0.000 & -0.69 & 3.81 & 3.12 \\
\hline $\begin{array}{c}\text { Spare parts service } \\
\text { level }\end{array}$ & 0.000 & -0.5 & 3.62 & 3.12 \\
\hline $\begin{array}{c}\text { Accessibility and } \\
\text { reliability levels }\end{array}$ & 0.000 & 0.98 & 3.80 & 4.78 \\
\hline $\begin{array}{c}\text { Cost of Support } \\
\text { Services }\end{array}$ & 0.331 & 1.5 & 3.34 & 4.84 \\
\hline Procurement Costs & 0.096 & -0.18 & 3.89 & 3.71 \\
\hline $\begin{array}{c}\text { Equipment Risk } \\
\text { Taking }\end{array}$ & 0.000 & -1.06 & 3.71 & 2.65 \\
\hline Cost of Capital & 0.201 & 0.6 & 3.67 & 4.27 \\
\hline
\end{tabular}

According to the table above, 3 out of 8 components have a sig value greater than 0.05 , which means that the claim about them is accepted. However, in other cases, the claim is rejected and there is a gap between the current and the desired situation. In the following, the physical assets of the studied company (North Drilling Company) were reviewed and evaluated in 2018 (before the implementation of physical asset management) and 2019 (after the implementation of physical asset management) using these indicators.

\section{CONCLUSIONS}

As an item, object, or entity that has potential or real value to the organization, the value of the asset varies between different organizations and their stakeholders and may be tangible or intangible, financial or non-financial, and may change during the life of the asset.

Through reviewing and improving processes, procedures and performance of assets, improving financial performance, risk management, improving services and products, improving customer satisfaction, increasing equipment safety and assisting managers in informed investment decisions on assets, physical asset management system significantly contributes to the effectiveness, efficiency and productivity, as well as improving the achievement of organizations' objective goals. The present study aimed to investigate and evaluate the physical asset management system in oil and gas equipment industries emphasizing the drilling industry. For a case study, the North Drilling Company has been selected as one of the upstream companies in the oil industry. Eight indicators have been selected as important indicators for evaluating the physical asset system in oil and gas equipment industries. Fig. 2 shows the graph of expert opinions using the fuzzy Delphi method.

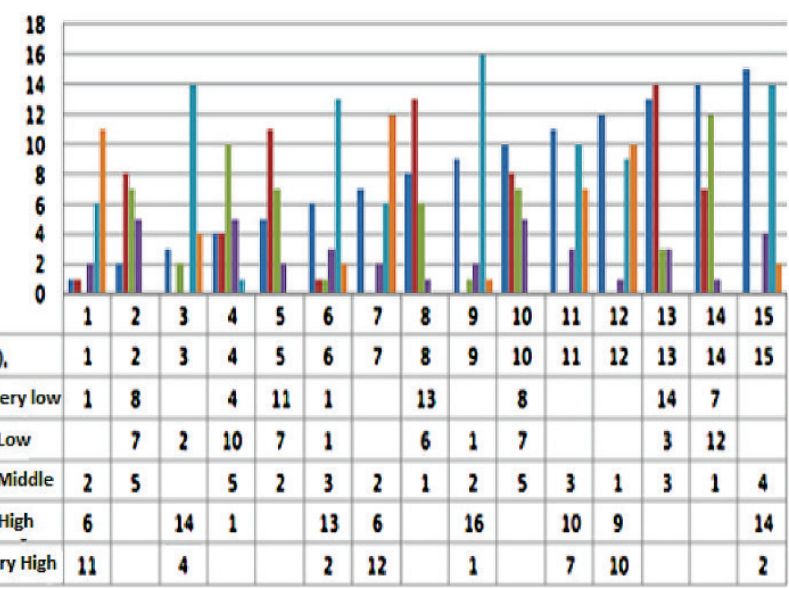

Figure 2 The graph of the expert opinions in the fuzzy Delphi stage

According to the Tab. 5 and the fact that the condition of consensus or agreement was that $70 \%$ of the experts gave the same answer to one of the options for each question, the amount of consensus was examined; considering that the amount of consensus in the table below is some questions, the questionnaire did not reach the $70 \%$ consensus level, so the second round of the questionnaire started and the general results of the first questionnaire were presented to the experts and again, according to the results of the first questionnaire, they answered the questions of the second questionnaire.

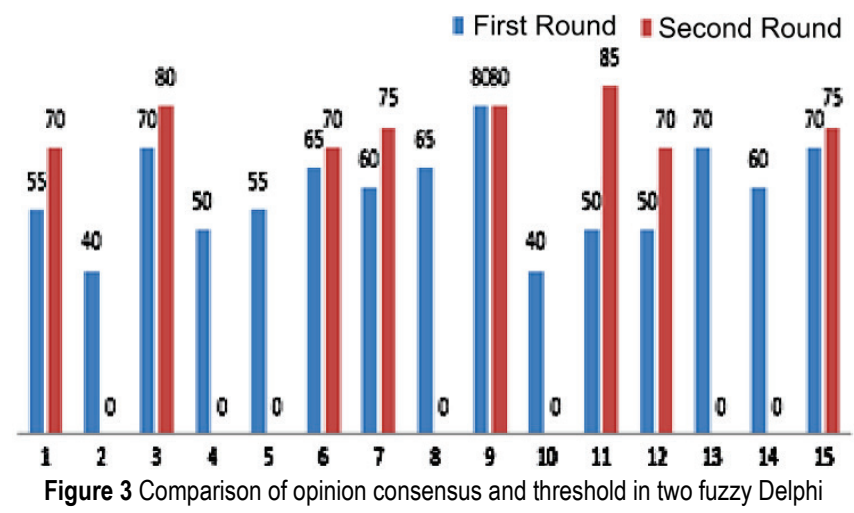

The indicators whose threshold is less than 0.70 in the first round have been removed from the second round and their value is considered zero. Annual maintenance costs, equipment life cycle costs, capital sleep costs, monthly access and reliability levels, equipment risk, annual logistics costs, support service costs and spare parts service levels are eight indicators agreed upon by experts. Second, the fuzzy SWARA method was used to weigh the indices and 
determine the importance of each index. The weight obtained was determined based on the following graph.

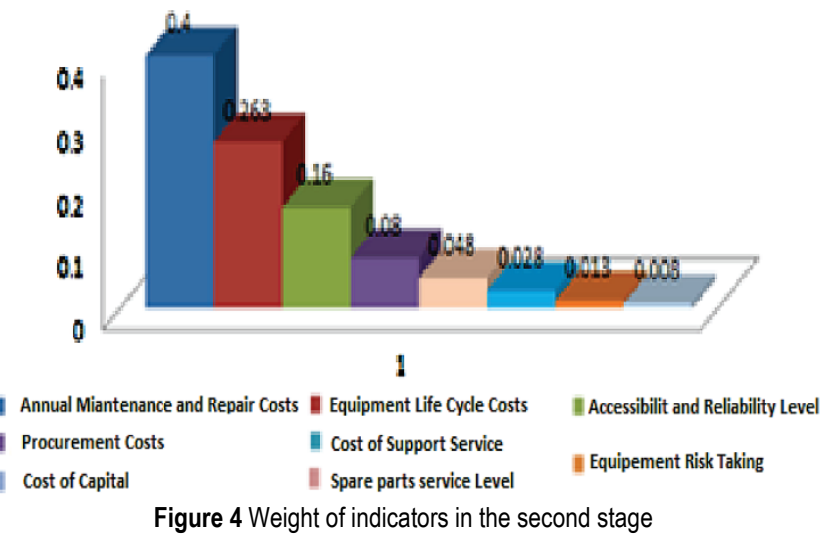

Annual maintenance and repair costs with a weight of 0.400 have the highest weight or in other words in priority the most important indicator in the management of physical assets in the study area. The cost of support services index with a weight of 0.008 has the lowest weight among the selected indicators. Finally, in the third step, the gap between the current and desired situation was analysed based on the selected indicators in the studied company. At this stage, analyses were performed based on the population and the selected statistical sample and sample t-test. From the eight selected indicators, equipment risk indicators, annual procurement cost, and spare parts service level with the significance of $0.331,0.096$, and 0.201 , respectively, have no gap between them. However, about other indicators, there is a gap between the current and the desired situation. In order to better study and compare its future results with this research, the following subjects are suggested to the researchers:

- Explaining the performance evaluation model utilizing other models of physical assets in the oil and gas industry

- Evaluating and prioritizing physical asset development indicators with approaches other than resource-based view and utilizing fuzzy SWARA, fuzzy EDAS and other methods.

- Investigating and explaining the control of costs related to drilling services in order to improve the physical asset management system

\section{REFERENCES}

[1] PAS 55-1:2008. (2008). Asset Management, Part 1: Specification for the optimized management of physical assets, Institute of Asset Management (IAW), ICS code: 03.100.01

[2] ... (2019). Strategic document for the management of physical assets of the Ministry of Oil.

[3] ... (2019). General policy document and requirements of the physical assets management system of the Ministry of Oil approved by the High Official of the Ministry.

[4] The book "TPM" by Nasser Mohammadi Jalali and Dr. Mehpikar of the National Library of Iran, TS-678-2 92

[5] PAS 55-2:2008, Asset Management. (2008). ICS code: 03.100.01 No Copying without BSI Permission except as
Permitted by Copyright Law Part 2: Guidelines for the application of PAS 55-1

[6] Asset Management Consulting Limited (AMCL). (2013). A report for the Office of Rail Regulation and Network Rail from: 350 Pages

[7] Gupta, R. K. (2013). Process Based Business Excellence Model. Asian Journal of Research in Business Economics and Management, 3(5), 132-149.

[8] ... (2014). The Asset Management Landscape, second edition, English version, Global Forum on Maintenance and Asset Management (GFMAM), https://gfmam.org/sites/default/files/ 2019-05/GFMAMLandscape_SecondEdition_English.pdf

[9] Campbell, J. D., Jardine, A. K. S., \& McGlynn, J. (2015). Asset Management Excellence: Optimizing Equipment Life-Cycle Decisions, third edition, 470 pages.

[10] ... (2017). Asset Management \& Performance Metrics Collaborative, IPL, Cause No. 44602/44576, 1-173. https:/www.in.gov/iurc/files/2017-03-31,-044576_IPL_ Compliance-Filing-Asset-Management-And-PerformanceMetrics-Collaborative.pdf

[11] Creamer, J. (2020). Integrated Upstream Asset Management. Empowering Pumps \& Equipment Staff. https://empoweringpumps.com/schneider-electric-integratedupstream-asset-management/

[12] Klabnik, S. (2012). Asset Life Cycle Management Optimizes Performance, Exclusive Story.

[13] Vahedia M. \& Movahedi, M. M. (2018). Evaluating and Prioritizing Asset Management Excellence Model Based on Critical Criteria Using the Combination of DEMATEL and ANP Techniques. PBR (Petroleum, Business, Review), 2(3), 56-65.

[14] Asurdzic, N. (2019). Physical Asset Management of Complex Infrastructures: Strategies, methodologies and tools for Effective Service Management. http://summerschoolaidi.it/edition-2015/images/paper2012/2.5.pdf

[15] Campbell, J. D. (1999). Uptime: Strategies for Excellence in Maintenance Management. Eisenhardt, M. K. (1989). Agency theory: An assessment and review. Academy of Management Review, 14(1), 57.

[16] Forza, C. (2002). Survey research in operations management: a process-based perspective. Università di Padova, Vincenca, Italy, International Journal of Operations \& Production Management, 22(2). 152-194.

[17] Fulmer, J. (2009). What in the world is infrastructure? Guest article investment strategy, PEI Infrastructure Investor, 30-32.

[18] ... (2006). Engineering Asset Management. Proceedings of the $1^{\text {st }}$ World Congress on Engineering Asset Management (WCEAM), 11-14 July 2006, Editors: Mathew, J., Kennedy, J., Ma, L., Tan, A., \& Anderson, D. Springer, 163-168.

[19] Miller, D. \& Friesen, P. H. (1982). Innovation in Conservative and Entrepreneurial Firms: Two Models of Strategic Momentum. Strategic Management Journal, 3, 1-25.

[20] Mollentze, F. J. (2005). Asset Management Auditing - The Roadmap to Asset Management Excellence, Department of Engineering and Technology Management, University of Pretoria, South Africa.

[21] Jabiri, N. Z., Jaafari, A., Platfoot, R., \& Gunaratram, D. (2005). Promoting Asset Management Policies by Considering OEE in Products' TLCC Estimation. Proceedings. 2005 IEEE International Engineering Management Conference, Vol. 2, 480-484. https://doi.org/10.1109/IEMC.2005.1559194

[22] Emmanouilidis, C. \& Komonen, K. (2013) Physical Asset Management Practices in Industry: Comparisons between Greece and Other EU Countries. In: Prabhu V., Taisch M., Kiritsis D. (eds) Advances in Production Management 
Systems. Sustainable Production and Service Supply Chains. APMS 2013. IFIP Advances in Information and Communication Technology, vol. 415. Springer, Berlin, Heidelberg. https://doi.org/10.1007/978-3-642-41263-9_63

[23] Vahedi, M. \& Movahedi, M. M. (2018). Evaluating and Prioritizing Asset Management Excellence Model Based on Critical Criteria Using the Combination of DEMATEL and ANP Techniques. PBR (Petroleum, Business, Review), 2(3), 56-65.

http://pbr.put.ac.ir/article_93429_c4e7b6a331c704c55b0b710 ad12c8a27.pdf

[24] Kagiso Le Tswelelopele. (2019). Volume 6: Movable Asset Management. Accessed: http://www.nwpg.gov.za/treasury/ procurement 2/documents/SCM\%20PRACTITIONER\%20AR EA/SCM\%20Policy\%20Management/Blue\%20print\%20syste $\mathrm{m} /$ VOLUME\%206.pdf

[25] Lee, W.-B., et al. (2004). System Oriented Plant Maintenance, KHNP. https://doi.org/10.4028/www.scientific.net/KEM.297300.2693

\section{Authors' contacts:}

Hassan Adshirinpour, Master

Department of Industrial Management,

Science and Research Branch, Islamic Azad University,

Daneshgah Blvd, Simon Bulivar Blvd, Tehran, 1477893855, Iran

h.adshirinpour@gmail.com

Mohammad Mehdi Movahhedi, Associate Professor Dr.

(Corresponding author)

Faculty of Industrial Management,

Islamic Azad University, Firoozkuh Branch,

Firoozkuh, Iran

mmmovahedi@gmail.com

Hedieh Divsalar, Associate Professor Dr.

Faculty of Science and New Technologies,

Islamic Azad University, Medical Science Branch,

Shariati St, Tehran, 19395/1495, Iran

hediehdivsalar@yahoo.com

Shahla Sohrabi, Assistant Professor Dr.

Department of Management, West Tehran Branch,

Islamic Azad University,

Tehran, Iran

modiran77@gmail.com 